\title{
Catch-up growth in childhood and death from coronary heart disease: longitudinal study
}

\author{
J G Eriksson, T Forsén, J Tuomilehto, P D Winter, C Osmond, D J P Barker
}

\begin{abstract}
Objective To examine whether catch-up growth during childhood modifies the increased risk of death from coronary heart disease that is associated with reduced intrauterine growth.

Design Follow up study of men whose body size at birth was recorded and who had an average of 10 measurements taken of their height and weight through childhood.

Setting Helsinki, Finland.

Subjects 3641 men who were born in Helsinki University Central Hospital during 1924-33 and who
\end{abstract} went to school in Helsinki.

Main outcome measures Hazard ratios for death from coronary heart disease.

Results Death from coronary heart disease was associated with low birth weight and, more strongly, with a low ponderal index at birth. Men who died from coronary heart disease had an above average body mass index at all ages from 7 to 15 years. In a simultaneous regression the hazard ratio for death from the disease increased by 14\% (95\% confidence interval $8 \%$ to $19 \% ; \mathrm{P}<0.0001)$ for each unit $\left(\mathrm{kg} / \mathrm{m}^{3}\right)$ decrease in ponderal index at birth and by $22 \%(10 \%$ to $36 \% ; \mathrm{P}=0.0001)$ for each unit $\left(\mathrm{kg} / \mathrm{m}^{2}\right)$ increase in body mass index at 11 years of age. Body mass index in childhood was strongly related to maternal body mass index, which in turn was related to coronary heart disease. The extent of crowding in the home during childhood, although related to body mass index in childhood, was not related to later coronary heart disease.

Conclusion The highest death rates from coronary heart disease occurred in boys who were thin at birth but whose weight caught up so that they had an average or above average body mass from the age of 7 years. Death from coronary heart disease may be a consequence of poor prenatal nutrition followed by improved postnatal nutrition.

\section{Introduction}

People who had low birth weight, or who were thin or short at birth as a result of reduced intrauterine growth, have increased rates of coronary heart disease. $^{12}$ They also have an increased prevalence of biological risk factors for the disease-namely, hypertension, non-insulin dependent diabetes, and abnormalities in lipid metabolism and blood coagulation. ${ }^{3}{ }^{4}$ These associations have been replicated in studies in a number of countries. ${ }^{5-8}$ They have led to the hypothesis that coronary heart disease originates in utero through the persistence of endocrine, physiological, and metabolic adaptations that the fetus makes when it is undernourished. ${ }^{4}$

We do not yet know whether the increased risk of coronary heart disease associated with reduced prenatal growth is modified by growth during childhood. This may be important because optimising childhood growth through improved nutrition and living conditions might reduce the risk of the disease. We have previously described associations between size at birth and death from coronary heart disease in a cohort of men born in Helsinki, Finland, during 1924 to $1933 .{ }^{9}$ The growth of these men through childhood, and their living conditions, were recorded. The men had an average of 10 serial measurements taken of height and weight between the ages of 7 and 15 years. This allowed us to examine, for the first time, the association between childhood growth and death from coronary heart disease, taking into account size at birth.

\section{Subjects and methods}

Subjects-We studied a sample of men who were born at the Helsinki University Central Hospital and who went to school in Helsinki. Details of the birth records kept in the hospital have been described. ${ }^{9}$ Data on the mothers consisted of age, parity, height, date of the last menstrual period, and age at menarche, together with body weight measured on admission in labour. Data on their newborn babies consisted of birth weight, placental weight, and length and head circumference. We studied men who were born at the hospital during 1924 to 1933, who went to school in Helsinki, and who were still resident in Finland in 1971. School health records for all children attending schools in Helsinki are stored in the city archives. We identified 3975 men from the birth and school health records, and we used the population register that covers the whole Finnish population to trace 3641 (92\%) of them. The mean birth size of men who were traced and not traced was similar. This cohort comprised 339 more men than were included in our first report because further information has allowed linkage of additional birth and school records.

Protocol-For each of the 3641 men there was an average of 10 (SD 4) measurements of height and weight between the ages of 6 and 16 years, giving a total of 37939 measurements. These were recorded during periodic school medical examinations. At the first examination, most commonly at the age of 7 years, school nurses recorded the number of other people living in the child's house, and the number of rooms. Since 1971 all residents of Finland have been assigned a unique personal identification number. By using this number we identified all deaths among the men during 1971-95. Deaths in Finland are recorded in the national mortality register. The register was computerised in 1971, and causes of death were recorded according to ICD-8 (international classification of diseases, eighth revision) until 1986; thereafter ICD-9 was used until the end of 1995. The first three digits from the primary cause of death in ICD- 8 and ICD-9 were used for identifying deaths from coronary heart disease (410-414). Using the father's occupation, which

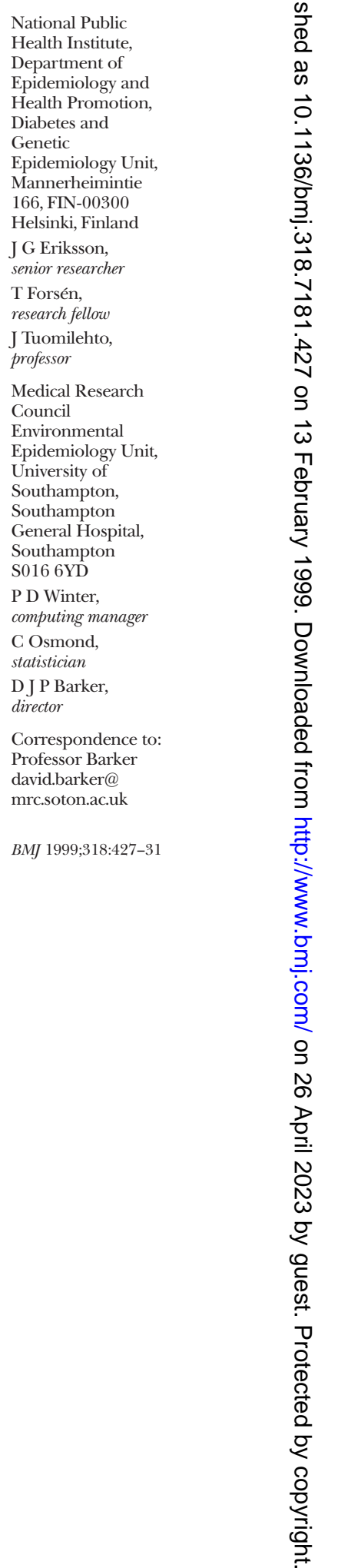


Table 1 Maternal, neonatal, and childhood characteristics of 3641 men born at Helsinki University Central Hospital during 1924-33

\begin{tabular}{|c|c|c|c|}
\hline Characteristics & Mean (SD) & Range & $\begin{array}{l}\text { No of missing } \\
\text { values }\end{array}$ \\
\hline \multicolumn{4}{|l|}{ Mother } \\
\hline Height $(\mathrm{m})$ & $1.58(0.06)$ & $1.31-1.85$ & 249 \\
\hline Weight in late pregnancy $(\mathrm{kg})$ & $67.3(9.2)$ & $44-129$ & 265 \\
\hline Body mass index in late pregnancy $\left(\mathrm{kg} / \mathrm{m}^{2}\right)$ & $26.8(3.2)$ & $16.6-49.0$ & 292 \\
\hline Age (years) & $27.4(5.7)$ & $16-46$ & 3 \\
\hline Age at menarche (years) & $15(1.7)$ & $9-22$ & 16 \\
\hline$\%$ primiparous & 44 & & 1 \\
\hline \multicolumn{4}{|l|}{ Neonate } \\
\hline Birth weight $(\mathrm{g})$ & $3443(515)$ & $1100-5120$ & 0 \\
\hline Head circumference $(\mathrm{cm})$ & $34.9(1.4)$ & $28.0-40.0$ & 12 \\
\hline Birth length $(\mathrm{cm})$ & $50.2(1.9)$ & $39.0-57.0$ & 15 \\
\hline Ponderal index $\left(\mathrm{kg} / \mathrm{m}^{3}\right)$ & $27.0(2.5)$ & $14.9-52.3$ & 15 \\
\hline Placental weight $(\mathrm{g})$ & $634(127)$ & $240-1440$ & 3 \\
\hline Length of gestation (days) & $275(15)$ & $197-307$ & 182 \\
\hline \multicolumn{4}{|l|}{ Child $^{*}$} \\
\hline \multicolumn{4}{|l|}{ Height $(\mathrm{m})$ at: } \\
\hline 7 years & $1.19(0.05)$ & $1.00-1.37$ & 0 \\
\hline 11 years & $1.39(0.06)$ & $1.15-1.60$ & 0 \\
\hline 15 years & $1.60(0.09)$ & $1.30-1.95$ & 0 \\
\hline \multicolumn{4}{|l|}{ Weight $(\mathrm{kg})$ at: } \\
\hline 7 years & $22.0(2.5)$ & $14.9-37.8$ & 0 \\
\hline 11 years & $31.8(4.0)$ & $20.0-58.7$ & 0 \\
\hline 15 years & $47.5(8.5)$ & $26.4-109.9$ & 0 \\
\hline \multicolumn{4}{|l|}{ Body mass index $\left(\mathrm{kg} / \mathrm{m}^{2}\right)$ at: } \\
\hline 7 years & $15.4(1.1)$ & $12.1-23.6$ & 0 \\
\hline 11 years & $16.4(1.3)$ & $12.6-26.9$ & 0 \\
\hline 15 years & $18.4(1.7)$ & $13.0-32.3$ & 0 \\
\hline Crowdingt & $2.8(1.6)$ & $0.1-11$ & 593 \\
\hline No of people in house & $4.5(1.7)$ & $1-27$ & 587 \\
\hline No of rooms in house & $1.7(0.9)$ & $1-14$ & 546 \\
\hline
\end{tabular}

*Height, weight, and body mass index at each age were estimated from serial measurements on each child. †No of people/No of rooms. Mean value is geometric mean.

Table 2 Hazard ratios for coronary heart disease according to size at birth and body mass index at age 11 years

\begin{tabular}{|c|c|c|c|c|}
\hline Variable & No of men & $\begin{array}{l}\text { Hazard ratio } \\
\text { (No of deaths) }\end{array}$ & $P$ for trend & $\begin{array}{l}\text { Adjusted for } \\
\text { gestation }\end{array}$ \\
\hline \multicolumn{5}{|c|}{ Birth weight $(g)$} \\
\hline$\leqslant 2500$ & 145 & $1.13(11)$ & \multirow{5}{*}{0.15} & \multirow{5}{*}{0.05} \\
\hline-3000 & 557 & $1.23(48)$ & & \\
\hline-3500 & 1328 & $1.46(133)$ & & \\
\hline-4000 & 1165 & $1.11(88)$ & & \\
\hline$>4000$ & 446 & $1.00(30)$ & & \\
\hline \multicolumn{5}{|c|}{ Ponderal index at birth $\left(\mathrm{kg} / \mathrm{m}^{3}\right)$} \\
\hline$\leqslant 25$ & 724 & $2.07(82)$ & \multirow{4}{*}{$<0.0001$} & \multirow{4}{*}{$<0.0001$} \\
\hline-27 & 1099 & $1.75(106)$ & & \\
\hline-29 & 1081 & $1.33(80)$ & & \\
\hline$>29$ & 722 & $1.00(41)$ & & \\
\hline \multicolumn{5}{|c|}{ Body mass index $\left(\mathrm{kg} / \mathrm{m}^{2}\right)$ at age 11} \\
\hline$\leqslant 15.5$ & 887 & $1.00(59)$ & \multirow{4}{*}{0.004} & \multirow{4}{*}{ - } \\
\hline-16.5 & 1160 & $1.28(99)$ & & \\
\hline-17.5 & 992 & $1.35(89)$ & & \\
\hline$>17.5$ & 602 & $1.53(63)$ & & \\
\hline
\end{tabular}

was on 3375 of the birth records, we grouped the men according to a social classification used by the Central Statistical Office. Overall, 84\% (2836) of the fathers were labourers and $11.5 \%$ (387) were classified as lower middle class. Together these constitute the lower social class as opposed to the upper social class, which is subdivided into upper middle class $(2.6 \%, 86)$ and self employed $(1.6 \%, 55)$.

Statistical analysis-The number of deaths from coronary heart disease was compared with that expected from Finnish national rates for men of corresponding age and year of birth. Death rates were expressed as standardised mortality ratios, the national average being 100 . We examined the trends in standardised mortality ratios with neonatal measurements. Tests for trend were based on the corresponding log linear model and on Cox's proportional hazards model, using either continuous or categorical variables and their interactions. We converted each measurement for height, weight, and body mass index for each boy to a $\mathrm{Z}$ score, using the method of Royston. ${ }^{10}$ We interpolated between successive $\mathrm{Z}$ scores with a piecewise linear function and so obtained a $\mathrm{Z}$ score at each birthday from 7 to 15 years of age. We back transformed these $\mathrm{Z}$ scores to obtain the corresponding height, weight, and body mass index at these ages.

\section{Results}

Table 1 shows the maternal, neonatal, and childhood characteristics of the 3641 men. Overall, 1084 (30\%) of the men had died, $310(8.5 \%)$ from coronary heart disease. The mean age at death from coronary heart disease was 58 years (range 38 to 71 years), and the standardised mortality ratio was 83 (95\% confidence interval 74 to 93 ).

Size at birth-Table 2 shows hazard ratios for coronary heart disease according to size at birth. The ratios decreased with increasing birth weight, although this was not statistically significant. As we have previously described, ${ }^{9}$ ratios decreased more steeply with increasing ponderal index (birth weight/length ${ }^{3}$ ). The ratios also decreased with increasing placental weight. There were no trends with head circumference or length at birth. Hazard ratios were not related to the length of gestation, although the highest ratios were in men born after 41 weeks. After adjustment for the length of gestation, the associations with birth weight and ponderal index strengthened (table 2), and there was a significant association with placental weight $(\mathrm{P}=0.03)$.

\section{Growth in childhood}

From 7 to 15 years of age the average height of men who died from coronary heart disease was similar to that of the other men in the cohort. Figure 1 shows, however, that at every age the men who died from coronary heart disease had a higher body mass index than the other men in the cohort. The association was stronger in older children, many of whom would have experienced puberty. The association was strengthened by adjustment for ponderal index at birth, because babies born with a low ponderal index tended to have a low body mass index throughout childhood. The correlation between ponderal index at birth and body mass index at age 11 years, for example, was 0.18 $(\mathrm{P}<0.0001)$. The adjusted hazard ratio for death from coronary heart disease associated with a 1 SD increase in body mass index was 1.15 (1.03 to 1.29) at 7 years of age and 1.18 (1.07 to 1.31$)$ at 15 years of age.

Table 2 shows the effects of body mass index at 11 years of age, the middle of the age range, on hazard ratios for death from coronary heart disease. Table 3 shows the combined effects of body mass index at 11 years of age and ponderal index at birth. The ratios were adjusted for length of gestation. The hazard ratio 


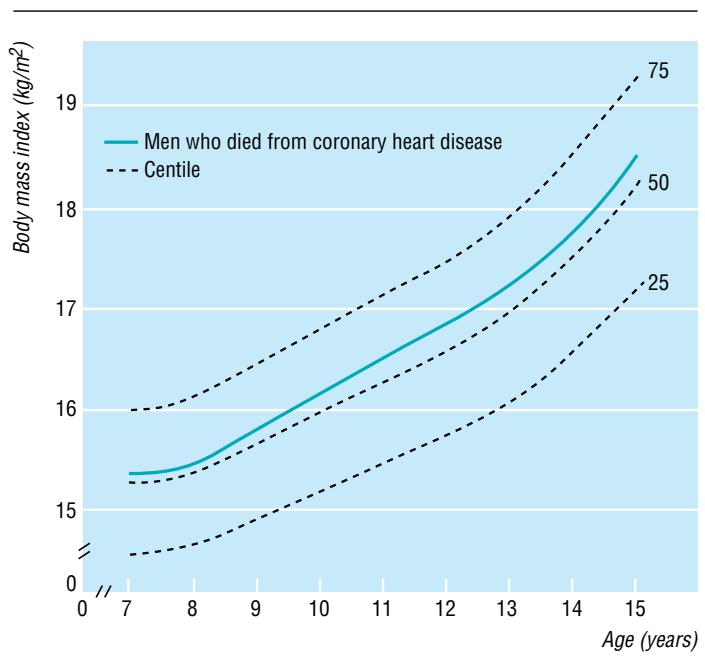

Fig 1 Body mass index during childhood in men who later died from coronary heart disease compared and centiles for body mass index of all men in cohort $(n=3641)$

for men with the highest ponderal index at birth and the lowest body mass index at 11 years of age was set at 1.0. The highest hazard ratio of 5.3 was in men with the lowest ponderal index at birth and the highest body mass index at 11 years of age. In a simultaneous regression, the hazard ratio for death from coronary heart disease increased by $14 \% \quad(8 \%$ to $19 \%$; $\mathrm{P}<0.0001)$ for each unit $\left(\mathrm{kg} / \mathrm{m}^{3}\right)$ decrease in ponderal index at birth and by $22 \%(10 \%$ to $36 \% ; \mathrm{P}=0.0001)$ for each unit $\left(\mathrm{kg} / \mathrm{m}^{2}\right)$ increase in body mass index at 11 years of age. Figure 2 further illustrates these associations, showing that boys born with a high ponderal index had a low risk of coronary heart disease, even if they became overweight in childhood, whereas the high risk of those who were thin at birth was further increased if they became even moderately overweight during childhood. The results for body

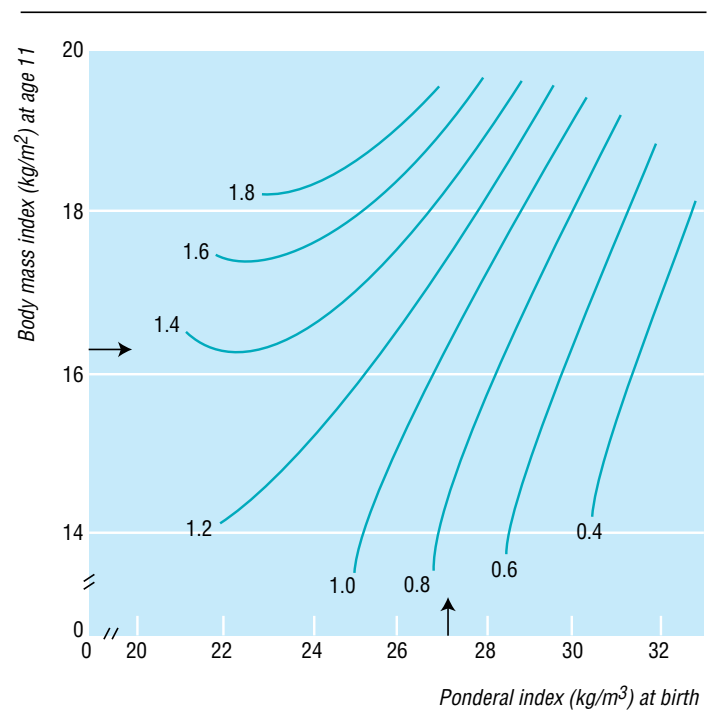

Fig 2 Hazard ratios for death from coronary heart disease according to ponderal index at birth and body mass index at age 11 years, adjusted for length of gestation. Arrows indicate average values
Table 3 Hazard ratios for death from coronary heart disease according to ponderal index at birth and body mass index at age 11 years, adjusted for length of gestation

\begin{tabular}{lcccc} 
& \multicolumn{4}{c}{ Body mass index* $\left(\mathbf{k g} / \mathbf{m}^{\mathbf{2}}\right)$ ( $\mathbf{N o}$ of deaths) } \\
\cline { 2 - 5 } Ponderal index $\left(\mathbf{k g} / \mathbf{m}^{\mathbf{3}}\right)$ & $\leqslant \mathbf{1 5 . 5}$ & $-\mathbf{1 6 . 5}$ & $-\mathbf{1 7 . 5}$ & $>\mathbf{1 7 . 5}$ \\
\hline$\leqslant 25$ & $2.7(21)$ & $3.3(26)$ & $3.7(19)$ & $5.3(14)$ \\
\hline-27 & $1.5(14)$ & $3.2(40)$ & $4.0(35)$ & $2.7(14)$ \\
\hline-29 & $2.2(17)$ & $1.6(18)$ & $1.8(19)$ & $3.2(21)$ \\
\hline$>29$ & $1.0(4)$ & $1.7(11)$ & $1.5(12)$ & $1.9(12)$ \\
\hline
\end{tabular}

${ }^{*}$ Cut off points are approximately quartiles.

mass index at ages other than 11 years were similar to those shown in table 3 and figure 2 .

Maternal characteristics-The mothers' body mass indices were strongly and inversely related to their age at menarche and strongly positively related to the height and body mass index of their sons $(\mathrm{P}<0.0001$ for body mass indices at all ages). As described in our previous report, high maternal body mass was also strongly related to increased hazard ratios for coronary heart disease among the men, an effect which was confined, however, to mothers of below average stature $(<1.58 \mathrm{~m}))^{9}$ The effect of maternal body mass index on coronary heart disease was only partly dependent on its effect on body mass in childhood. In a simultaneous regression the hazard ratios for coronary heart disease increased by $15 \%(3 \%$ to $28 \% ; \mathrm{P}=0.02)$ for every $\mathrm{SD}$ increase in maternal body mass index, and by $13 \%(1 \%$ to $26 \% ; \mathrm{P}=0.03$ ) for every $\mathrm{SD}$ increase in body mass index at 11 years of age.

Crowding in the home and social class during childhood-Table 1 shows the average number of inhabitants and rooms in the homes where the men grew up; $46 \%$ (1435) lived in homes with only one room. We used the ratio of the number of inhabitants to the number of rooms as an index of crowding. Table 4 shows that families living in less crowded homes were of higher social class, and the sons were taller and had a higher body mass index at 11 years of age. The results at ages other than 11 years were similar. We used multiple linear regression to examine the simultaneous effects of the mother's body mass index and crowding on the boy's body mass index at 11 years of age. The effect of the mother's body mass was much stronger $(\mathrm{P}<0.0001)$ than that of crowding $(\mathrm{P}=0.01)$. Death from coronary heart disease was unrelated to the number of inhabitants or rooms or to crowding; in a simultaneous analysis it remained unrelated whereas the association with increased mothers' body mass was significant $(\mathrm{P}=0.003)$.

\section{Discussion}

In Finland, men who had low birth weight and were thin at birth, but had an above average body mass in childhood, had high death rates from coronary heart disease. The association between coronary heart disease and size at birth in these men was consistent with findings in two cohorts in the United Kingdom, totalling 13249 men, ${ }^{2}$ and in a cohort of 7012 men in Sweden. $^{5}$ The association was strengthened by adjustment for length of gestation.

We were able to trace $92 \%$ of the men in the cohort Our study was restricted to men who were born in Helsinki University Central Hospital and who went to school in Helsinki. The fathers of $84 \%$ of the men were 
Table 4 Crowding in home, fathers' social class, sons' heights and body mass indices at age 11 years, and hazard ratios for death from coronary heart disease in sons

\begin{tabular}{lccccc}
$\begin{array}{l}\text { No of people } \\
\text { per room }\end{array}$ & No of men & $\begin{array}{c}\text { \% fathers in } \\
\text { upper social } \\
\text { class }\end{array}$ & $\begin{array}{c}\text { Sons' height } \\
\text { (cm) }\end{array}$ & $\begin{array}{c}\text { Sons' body mass } \\
\left.\text { index } \mathbf{( k g} / \mathbf{m}^{2}\right)\end{array}$ & $\begin{array}{c}\text { Sons' hazard ratio } \\
\text { for death from } \\
\text { coronary heart } \\
\text { disease }\end{array}$ \\
\hline-1.5 & 395 & 10.0 & 140.6 & 16.5 & 1.00 \\
\hline-2.5 & 946 & 5.2 & 139.6 & 16.4 & 1.19 \\
\hline-3.5 & 791 & 1.7 & 138.7 & 16.5 & 1.11 \\
\hline-4.5 & 521 & 1.9 & 138.8 & 16.4 & 1.06 \\
\hline$>4.5$ & 395 & 2.1 & 136.8 & 16.2 & 0.67 \\
\hline All & 3048 & 4.0 & 139.0 & 16.4 & - \\
\hline $\mathrm{P}$ for trend & - & $<0.0001$ & $<0.0001$ & 0.003 & 0.11 \\
\hline
\end{tabular}

classed as labourers. The men may be unrepresentative of all men living in Helsinki, although we know that early this century around $60 \%$ of men in the city were labourers. ${ }^{11}$ Likewise, the exceptionally overcrowded conditions in which the men grew up ( $46 \%$ having only one room in their homes) may not be typical of the city at that time. This would introduce a bias, however, only if the association between size at birth, childhood growth, and coronary heart disease differed between those born in the hospital and those born outside the hospital. We did not find an association between coronary heart disease and short stature, as has been found in studies of adults and in a cross sectional study of children. ${ }^{12-14}$ This may reflect the short average stature and poor living conditions of all the men in our cohort, whose average height at 11 years was $1 \mathrm{SD}$ below the mean for current growth charts in Finland.

\section{Catch-up growth}

Our study gives a unique picture of the fetal and childhood growth of men who were born in the early years of this century in poor socioeconomic conditions and who died from coronary heart disease. Men with the highest rates of the disease were thin at birth, but by the age of 7 years their weight had "caught up" and their body mass index was above average. Thereafter, up to 15 years of age, their body mass index tended to diverge further from the average. The association between a high body mass index in childhood and death from coronary heart disease is consistent with the known adverse effects of a high body mass index in adults. ${ }^{15}{ }^{16}$ It is also consistent with previous studies showing that high body mass index in childhood is related to increased death rates from all causes combined and from coronary heart disease. ${ }^{17-19}$

Because body mass index tends to "track" from the age of around 6 years into adult life, small increases in body mass in childhood could predict larger differences during adult life and the accompanying constellation of coronary risk factors. ${ }^{20-22}$ We do not have data on the body mass index of our subjects as adults. In the Harvard growth study of overweight adolescents, however, the effects of high body mass in childhood on coronary heart disease were independent of body mass as adults. ${ }^{18}$ Our findings show that the consequences of becoming overweight in childhood are conditioned by growth in utero and do not depend solely on the absolute level of overweight attained. In our data, if overweight is defined by a conventional criterion of a body mass index in childhood at or above the 85th centile, the hazard ratio for later coronary heart disease is small, around 1.2. This conceals the large hazard ratios, going up to around 5.0, among men who were thin at birth but caught up to become even moderately overweight in childhood.

Catch-up growth could be associated with adverse outcomes through altered body composition in later life. Babies who are thin at birth lack muscle. ${ }^{23}$ It is possible that if they develop a high body mass in childhood they have a disproportionately high fat mass. Another possibility is that accelerated postnatal weight gain is intrinsically damaging. In rats, the combination of prenatal undernutrition with retarded fetal growth, and good postnatal nutrition with accelerated growth, leads to striking reductions in life span. ${ }^{24}$ It is not known why catch-up growth is detrimental, but one speculation is that fetal growth restriction leads to reduced cell numbers, and subsequent catch-up growth is achieved by overgrowth of a limited cell mass. ${ }^{25} \mathrm{~A}$ third possible link between catch-up growth and coronary heart disease is that it reflects persisting changes in secretion of hormones, including insulin, insulin-like growth factor 1, and growth hormone, which are established in utero in response to undernutrition and influence both childhood growth and coronary heart disease. ${ }^{26}$

\section{Childhood nutrition and living conditions}

Whatever the mechanisms, our findings show that the combination of retarded fetal growth and accelerated weight gain between birth and 7 years of age is associated with a large increase in risk of death from coronary heart disease in men. The data suggest that accelerated weight gain among the men in our study resulted from good nutrition rather than from good living conditions with relative freedom from recurrent infection. The body mass indices of the boys were related to their mothers' body mass indices, as has been found in other studies. ${ }^{27}{ }^{28}$ We found that the mother's body mass index, which was measured in pregnancy, was inversely associated with age at menarche. Since menarcheal age is determined mainly by prepubertal body weight, ${ }^{29}$ this association shows that body mass in pregnancy reflected the mother's prepubertal growth and nutrition as well as her nutrition as an adult and her pregnancy weight gain. We conclude that death from coronary heart disease among the men in our study reflected the combination of poor prenatal nutrition with improved postnatal nutrition which was linked to their mothers having a high body mass. We do not know whether mothers with a high body mass influenced the postnatal catch-up growth of their children through direct effects during lactation or through better availability of food after weaning. Neither do we know the age before 7 years when catch-up in weight occurred. A child's body mass index decreases from infancy until around 6 years, and then increases. ${ }^{30}$ This increase is called the adiposity rebound, and later obesity may be related more to the timing of the rebound than to the subsequent energy intake.

The level of crowding in the home served as an index of living conditions. Crowding and mother's body mass index were independently related to the men's body mass indices in childhood. Men who grew up in overcrowded homes were short and had a low body mass index as boys. The level of crowding was 
Key messages

- Men who had low birth weight or were thin at birth have high death rates from coronary heart disease

- Death rates are even higher if weight "catches up" in early childhood

- Death from coronary heart disease may be a consequence of prenatal undernutrition followed by improved postnatal nutrition

- Programmes to reduce obesity among boys may need to focus on those who had low birth weight or who were thin at birth

not, however, related to later coronary heart disease Overcrowding reduces childhood growth partly because it is accompanied by increased rates of enteric and respiratory infection. ${ }^{31}$ Our findings suggest that it is nutrition rather than living conditions and infection in childhood that influences later coronary heart disease.

Coronary heart disease epidemics-In a previous report on this cohort, we described high death rates from coronary heart disease in men who were thin at birth but whose mothers were overweight in pregnancy. We concluded that overweight mothers afforded an adverse in utero environment, especially for fetuses whose development was constrained by poor placental growth. We have now identified that thin neonates are further disadvantaged if they have accelerated postnatal weight gain as a result of good nutrition. This may give further insight into the circumstances that lead to coronary heart disease epidemics in previously malnourished communities. The immediate consequence of improved nutrition is that not only mothers body mass indices but also children's body mass indices increase, whereas fetal nutrition remains limited by intergenerational constraints on placental growth. These changes are associated with a steep increase in coronary heart disease. Programmes to reduce obesity among boys may therefore usefully focus on those who had low birth weights or were thin at birth, and who therefore increase their risk of death from coronary heart disease by becoming even slightly overweight in childhood.

We thank Terttu Nopanen, Tiina Saarinen, Hillevi ÖfverströmAnttila, Liisa Toivanen, Arja Purtonen, Tiina Valle, Hanna Pehkonen, and Ulla Tarvainen for abstracting the data from the records. Sigrid Rosten was responsible for data management.

Contributors: All the authors took part in the design and analysis of the study and jointly wrote the paper. The data abstraction and linkage were supervised by JGE and TF. JGE $\mathrm{CO}$, and DJPB will act as guarantors for the paper.

Funding: British Heart Foundation, Jahnsson Foundation, Finska Läkaresällskapet, Orion Corporation Research Foundation, and Finnish Foundation for Cardiovascular Research. Competing interests: None declared.

1 Barker DJP, Osmond C, Winter PD, Margetts B, Simmonds SJ. Weight in infancy and death from ischaemic heart disease. Lancet 1989;2:577-80.

2 Martyn CN, Barker DJP, Osmond C. Mothers' pelvic size, fetal growth, and death from stroke and coronary heart disease in men in the UK. Lancet 1996;348:1264-8.

3 Hales CN, Barker DJP, Clark PMS, Cox LJ, Fall C, Osmond C, et al. Fetal and infant growth and impaired glucose tolerance at age $64 . B M J$ 1991;303:1019-22

4 Barker DJP. Fetal origins of coronary heart disease. BMJ 1995;311:171-4

5 Leon DA, Lithell H, Vagero D, McKeigue P, Koupilova I, Mohsen R, et al. Reduced fetal growth rate and increased risk of death from ischaemic heart disease: cohort study of 15000 Swedish men and women born 1915-29. BMJ 1998;317:241-5.

6 Rich-Edwards JW, Stampfer MJ, Manson JE, Rosner B, Hankinson SE Colditz GA, et al. Birth weight and risk of cardiovascular disease in a cohort of women followed up since 1976. BMJ 1997;315:396-400.

7 Law CM, Shiell AW. Is blood pressure inversely related to birth weight? The strength of evidence from a systematic review of the literature. $J$ Hypertens 1996;14:935-41.

8 Lithell HO, McKeigue PM, Berglund L, Mohsen R, Lithell UB, Leon DA. Relation of size at birth to non-insulin dependent diabetes and insulin concentrations in men aged 50-60 years. BMJ 1996;312:406-10.

9 Forsen T, Eriksson JG, Tuomilehto J, Teramo K, Osmond C, Barker DJP. Mother's weight in pregnancy and coronary heart disease in a cohort of Finnish men: follow up study. BMJ 1997;315:837-40.

10 Royston P. Constructing time-specific reference ranges. Stat Med 1991;10:675-90.

11 Yliaho T, Snellman H. Tehtaalainen Helsingissa. Helsinki: National Board of Antiquities, 1991.

12 Marmot MG, Shipley MJ, Rose G. Inequalities in death-specific explanations of a general pattern? Lancet 1984;i:1003-6.

13 Waaler HT. Height, weight and mortality. The Norwegian experience Acta Med Scand 1984;679:1-56.

14 Gunnell DJ, Smith GD, Frankel SJ, Nanchahal K, Braddon FEM, Peters T] Childhood leg length and adult mortality-follow-up of the Carnegie survey of diet and growth in pre-war Britain.J Epidemiol Community Health 1996;50:580-1

15 Wannamethee G, Shaper AG. Body weight and mortality in middle-aged British men: impact of smoking. BMJ 1989;299:1497-502.

16 Lee I-M, Manson JE, Hennekens CH, Paffenbarger RS. Body weight and mortality. A 27-year follow-up of middle-aged men. JAMA 1993;270:2823-8.

17 Nieto FJ, Szklo M, Comstock GW. Childhood weight and growth rate as predictors of adult mortality. Am J Epidemiol 1992;136:201-13.

18 Must A, Jacques PF, Dallal GE, Bajema CJ, Dietz WH. Long-term morbidity and mortality of overweight adolescents. New Engl J Med 1992;327:1350-5

19 Gunnell DJ, Frankel SJ, Nachahal K, Peters TJ, Davey Smith G. Childhood obesity and adult cardiovascular mortality: a 57-year follow-up study based on the Boyd Orr cohort. Am J Clin Nutr 1998;67:1111-8.

20 Guo SS, Roche AF, Chumlea WC, Gardner JD, Siervogel RM. The predictive value of childhood body mass index values for overweight at age 35 y. Am J Clin Nutr 1994;59:810-9.

21 Casey VA, Dwyer JT, Coleman KA, Valadian I. Body mass index from childhood to middle age: a 50-y follow-up. Am J Clin Nutr 1992;56:14-8.

22 Vanhala M, Vanhala P, Kumpusalo E, Halonen P, Takala J. Relation between obesity from childhood to adulthood and the metabolic syndrome: population based study. BMJ 1998;317:319.

23 Robinson SM, Wheeler T, Hayes M, Barker DJP, Osmond C. Fetal heart rate and intrauterine growth. Br J Obstet Gynaecol 1991;98:1223-7.

24 Hales CN, Desai M, Ozanne SE, Crowther NJ. Fishing in the stream of diabetes: from measuring insulin to the control of fetal organogenesis. Biochem Soc Trans 1996;24:341-50.

25 Pitts GC. Cellular aspects of growth and catch-up growth in the rat: a reevaluation. Growth 1986;50:419-36.

26 Barker DJP, Gluckman PD, Godfrey KM, Harding JE, Owens JA, Robinson JS. Fetal nutrition and cardiovascular disease in adult life. Lan cet 1993;341:938-41.

27 Whitaker RC, Wright JA, Pepe MS, Seidel KD, Dietz WH. Predicting obesity in young adulthood from childhood and parental obesity. New Engl J Med 1997;337:869-73.

28 Guillaume M, Lapidus L, Beckers F, Lambert A, Bjornthorp P. Familia trends of obesity through three generations: the Belgian-Luxembourg child study. Int J Obesity 1995;19(suppl 3):5-9S.

29 Frisch RE. The right weight:body fat, menarche and ovulation. Baillières Clin Obstet Gynaecol 1990;4:419-39.

30 Rolland-Cachera MF. Adiposity rebound and prediction of adult fatness. In: Uljasze KS, Johnston FE, Preece MA, eds. Human growth and development. Cambridge: Cambridge University Press, 1998;51-3.

31 Tanner JM. Foetus into man, 2nd ed. Ware: Castlemead,1989.

(Accepted 5 December 1998)

\section{Endpiece What is research?}

No scientist is admired for failing in the attempt to solve problems that lie beyond his competence. The most he can hope for is the kindly contempt earned by the Utopian politician. If politics is the art of the possible, research is surely the art of the soluble. Both are immensely practical-minded affairs.

P B Medawar, The Art of the Soluble (1967) 